\title{
The development of potential of students with a creative approach to education
}

\author{
Natalia Shutova ${ }^{1 *}$, Olga Suvorova ${ }^{2}$, Svetlana Sorokoumova ${ }^{3}$ and Natalia Ivanova ${ }^{2}$ \\ ${ }^{1}$ Lobachevsky University Russia, 603950, Nizhny Novgorod, Russia \\ ${ }^{2}$ Minin Nizhny Novgorod State Pedagogical University, 603600, Nizhny Novgorod, Russia \\ ${ }^{3}$ Russian State Social University, 107150, Moscow, Russia
}

\begin{abstract}
The article presents a fragment of a research project devoted to studying the impact of the musical influence system on the mental development of mentally retarded children. The author's approach to the criterion-oriented assessment of the levels of preschoolers' psychomotor development is applied. Three estimated levels of children's psychomotor development are used to assess both the actual features of this development and potential opportunities. The ascertaining experiment made it possible to reveal a significant motor impairment in mentally retarded children of the age of 6-7: difficulties in performing movements in accordance with the instructions; disorders of motor and spatial coordination; decreased motor memory; distortions of tempo, rhythm, and amplitude of movements (63.6\%). The development program "Music and Dance of My Body" made it possible to actualize the children's psychomotor potential through musical-motor improvisation. The program was aimed at developing a sense of rhythm, motor skills, forming correct posture, children's expressive movements and facial expressions, spatial coordination. The program allowed increasing the percentage of children with an average level of psychomotor development from $33.9 \%$ to $57.0 \%$. According to the results of the control stage, the dynamics of development were statistically significant at a high level of reliability $(\mathrm{p}=0.001)$.
\end{abstract}

\section{Introduction}

Preschool age is a period of intensive formation of a child's psyche and body. The psychomotor sphere plays a special role in the development of a preschooler's psyche.

In current Russian research, a high percentage of preschoolers (from $25 \%$ to $40 \%$ ) with low indicators of the psychomotor sphere development is stated: static and dynamic coordination, speed, clarity, smoothness of movements, fine motor skills; perception and memorization of movement patterns; efficiency and synchronicity of movements, motor self-control and motor self-regulation in general [1-4].

Mental retardation (MR) in preschoolers is manifested in all spheres of personal and general mental development, affecting, among other things, the psychomotor sphere. The

\footnotetext{
*Corresponding author: galsors@mail.ru
} 
percentage of insufficient development of psychomotor performance in such children is significantly lower than in children with normotypical development (NTD) $[1,2,5,6]$.

How can the decrease in psychomotor performance in mentally retarded children be explained? According to Luria's tradition of an integrative-holistic approach to the psyche and a syndromic-factor approach to developmental disorders, the maturation of motor cortex zones determines the development of the child's psyche as a whole [7]. Luria noted the close connection between fine motor skills and speech development, studied the role of speech regulation of movements in a complex, detailed voluntary activity [7]. Luria and Zaporozhets studied such determinants in the development of children's voluntary movements as imitation, orientation-research actions based on the perception of images and words, speech, purposeful activity, personality traits of a child [7, 8]. In mentally retarded children, all the mentioned indicators of mental development are reduced and, as a result, the quality of physical activity also decreases $[1,2]$. A number of researchers point to the immaturity of their voluntary sphere: it is difficult for the children to concentrate, they experience difficulties in switching attention and working according to the model and instructions, which also affects the solution of tasks requiring a motor response [9].

Thus, many authors have noted psychomotor underdevelopment in the syndrome of detected disorders in mentally retarded children. Researchers note the lack of sensorimotor coordination in this category of children, as well as motor awkwardness, impulsivity, emotional instability, increased fatigue. The research papers present data indicating that the vast majority of mentally retarded children have visual-spatial function under development, caused by impaired intersensory and sensorimotor integration and coordination [9]. The authors talk about a close relationship between the general mental and psychomotor development of mentally retarded children [5, 6, 9]. Insufficiency of mental and psychomotor processes directly affects the motor sphere formation among the children of this category. The motor sphere of mentally retarded children showed its qualitative originality: children lag behind in physical development, they have impaired regulation of voluntary movements, the technique of performing movements is not formed, there is a lack of motor qualities [4].

At the same time, children's psychomotor sphere is considered by researchers as a trigger mechanism for the restoration of interaction between the psychological and physiological subsystems of mental activity [6-8].

The authors consider the psychomotor development of a preschooler in dance-motor training as a mechanism for the integrated development of central spheres of the child's psyche, combining sensations, feelings, thinking, and movements into a holistic mental personality act.

The creation of optimal conditions for the implementation of age-related possibilities of mental development of a mentally retarded child as a subject of various types of activity, the search for effective means and methods of pedagogical influence on these children in teaching have currently received the significance of acute psychological and pedagogical problems. Their solution is complex and multifaceted.

In order to fulfill children's potential in the development of their activity and independence and optimize the process of their psychomotor development, special means are needed. In the authors' opinion, musical-motor improvisation can be one of the effective means.

Music, as well as movement, is an effective means of children's general mental development: cognitive [10-13]; linguistic [14]; social [15, 16]; emotional [17-19]; psychomotor development [20,21]. The mechanisms of interaction between music and movement were described by Sechenov; he was the first to point out the fact that all stimuli are of a mixed nature: muscular sense is necessarily mixed with an irritant adequate for eyes, ears, skin, etc. [22]. The informational aspect of music is read by the dynamic body 
state - co-intonation, pantomimic movement, therefore movement should be involved in musical education $[22,23]$.

The authors rely on the provisions of Russian psychology on the formation mechanisms of higher mental functions, where any of them initially develops in the external expanded activity, while the sensory level is the basis for their further development [7, 8, 23].

The authors assume that emotional-bodily sensations of music and musical impressions (motor-auditory, tactile, muscular ones) contribute to the child's emotional and motor response to music. The motor link of perception plays the role of a mechanism that transforms the hearing of music into its experience.

It is assumed that emotional-bodily sensations when perceiving music (motor-auditory, tactile, muscle ones) will contribute to the child's active emotional and motor response to music. The statement of a motor and dance task in the process of music perception (musical-motor improvisation) will positively influence the psychomotor development of mentally retarded preschoolers.

\section{Methods}

The purpose of this research is to study the possibilities of psychomotor development of mentally retarded preschoolers at the age of 6-7 in the context of the implementation of the author's musical-motor improvisation program "Music of My Body" [1, 2].

In the ascertaining experiment, the authors assessed the psychomotor development of children with MR (experimental group) and NTD (control group). A criterion-oriented diagnostic complex based on gaming psychomotor tests was used [1].

The methodology allows assessing three levels of psychomotor development of senior preschoolers: high, average, and low ones.

$A$ high level is determined when a child performs the proposed task in full; the methods of performance correspond to the instructions; the quality of movements is high, the actions are distinct, precise, balanced, well-coordinated; children have a formula of movements; the child acts actively and rhythmically; the speed and smoothness of transition from one movement to another are noted; positive emotions persist throughout the lesson; the child acts independently.

A low level shows a child's lag in all indicators: the child does not perform the task in full; disrupts movement patterns; low coordination of movements; many practice movements; there is no rhythm and formula of movements; there are a low speed and motor awkwardness in the transition from one movement to another; difficulties in a motor task reduce interest; neutral emotional background; the child needs the help of an adult at all stages of motor task performance.

An average level reflects the age norm of psychomotor development of a senior preschooler. The diagnostic program included three stages, each of which contained a number of tasks aimed at studying the main indicators of children's psychomotor development.

At the first stage, children's motor skills were assessed: static and dynamic coordination, motor memory, the quality of simultaneous movements.

At the second stage, children's mimic skills were assessed: mimic tests, mimic modeling of emotional states.

At the third stage, children's pantomime features in a static and dynamic state were assessed: posture, pose, gestures, gait.

The study involved 256 senior preschoolers at the age of 6-7, attending state preschool organizations, among which: 121 children made up the experimental group (EG) consisting of 58 boys and 63 girls with a diagnosis of MR; 135 children entered the control group (CG) consisting of 65 boys and 70 girls with NTD. 


\section{Results}

The ascertaining experiment made it possible to reveal a significant lag in the psychomotor development of mentally retarded preschoolers in comparison with normotypical children. The most pronounced differences were observed at the low $(64 \% / 23 \%)$ and average levels $(34 \% / 62 \%)$, as well as at the high level $(2 \% / 15 \%)$, respectively (Table 1$)$.

The average level of psychomotor development is typical for children with NTD, while mentally retarded children are characterized by a low level of motor skills and abilities. Some lag in psychomotor development is also noted among normotypical children (15\% high level). These results make it possible to state the insufficient effectiveness of traditional methods of children's psychomotor development.

The highest achievements in all categories of preschoolers from the EG and CG were observed in the development of facial expressions. However, mentally retarded children's mimic is less active and coordinated than that of normotypical children. Less successful achievements were also noted in preschoolers' pantomime development. Children's specific features of gait, gestures, mimic, poses are largely associated with common postural disorders (lordosis, kyphosis, scoliosis), which were significantly more common among mentally retarded children.

The following difficulties were revealed when the children performed the motor task: difficulties in performing voluntary movements in accordance with the instructions; violations of motor coordination and motor memory; inability to perform movements in accordance with spatial, temporal, and dynamic conditions; distortion of the tempo, rhythm, and amplitude of movements; forgetting the sequence of movements. Moreover, these difficulties were the most typical for mentally retarded children, which is associated with reduced opportunities for general self-regulation.

The goal of the experimental program was to optimize the psychomotor development of mentally retarded children through musical-motor improvisation.

The authors have created a complex musical-motor improvisation program "Music and Dance of My Body". The program was based on the author's program "Music of My Body" $[1,2]$ and solved the following tasks: development of children's sense of rhythm: uniform metric pulsation, perception of metric pattern, coordination of movements with the tempo and rhythm of music; development of children's motor skills in static and dynamic coordination, motor memory, speed and accuracy of reactions to sound signals, simultaneity of movements; formation of correct posture: normalization of muscle tone, training of individual muscle groups in order to strengthen them, development of a sense of balance, development of accuracy, smoothness of movement switching, overcoming motor automatism; development of movement and mimic expressiveness, the formation of the ability to convey the nature of music through mimic and plastic, the formation of the ability to create an expressive image, the formation of children's need for motor self-expression; mastering contact motor improvisation and communication using objects and toys $[1,2]$. In addition, the tasks of children's interaction and coordination development in the process of pair and group motor improvisation to music were set.

The program used author's music of different styles and eras (mainly miniatures), ethnic music, new age music. The program is designed for one lesson per week throughout the academic year. The lesson duration is $35-40$ minutes.

The principles of the individual (taking into account age, psychomotor, motor, psychological capabilities, and a state of health) and personalized approaches (taking into account nosology) were used.

Below are the goals and objectives of the program "Music and Dance of My Body" in working with mentally retarded children.

At the first stage, the goal was to develop a sense of rhythm in children. 
As a means of rhythmic learning, a rhythmic game was used on the body surface (the ensemble of "sounding gestures" by Ketman). Sounding gestures are a rhythmic game on the body surface: claps, slaps on the thighs, stamps with feet, snapping fingers, etc. Sounding gestures form the basis of motor improvisation, the development of voluntary and spontaneous motor skills. This technique relieved stress and brought children joy and pleasure.

In the first lessons, children were asked to copy the teacher's actions. Then the children invented and thought of various rhythmic and motor images.

At the second stage of the program implementation, plastic tasks were set, spontaneous plastic improvisation was used.

The activation of children's motor fantasy stimulated the desire of children to independently find the connection between sound, gesture, and movement, individual motor interpretation of music.

Motor improvisation is based on the ability to manipulate plastic templates [1, 2]. It was difficult for mentally retarded children to find plastic templates on their own. The teacher offered well-known dance techniques: "wave with a brush" ("swimming fish"), "wave with a hand" ("soaring wings"), "wave with a body" ("singing string"), "wave with a leg" ("dragon's tail"). Mastering plastic patterns required some effort and practice. Further, these patterns were applied spontaneously when the music was sounding, combined into chains of movements. After teaching children, the elements of motor expressiveness, creative tasks of their use in dance were set. Children acted spontaneously, subconsciously, based on auditory ideas, musical and motor memory.

The movements reflected the children's perception and emotional experience of the music. At first, children picked up the simplest music features (rhythm, tempo, general nature of movement, etc.). Then their movements got more precise, music perception deepened, emotional imagination became involved, an individual music interpretation was manifested in a special pattern of gesture and pantomime.

The third stage of the program was aimed at expanding the mimic and pantomimic repertoire of children.

Volitionally arising and spontaneously reproduced mimic expression affects a person's mood. Mentally retarded children often find it difficult to recognize the feelings of others; their own mimic repertoire is very limited.

Exercises based on the "mimic intonation" of music were used. First, the teacher showed various standards of emotions on an interactive screen in accordance with the nature of the sounding music (interest, joy, surprise, sadness, etc.). The mastery of the "music-emotions" connection allowed children subsequently to independently display the emotions evoked by music.

Further, on the interactive screen, children were shown simple standards of expressive movements for basic emotional states. Joy - the body opens up, the arms move up and to the sides, movements become active; sadness - the body stands still, the body closes, the head and hands come down.

Mastering the patterns of movements prepared the transition to solving creative tasks music-motor improvisation on various musical themes and images ("Dance of Funny Dolphins", "The Joy of Spring in Songs of Birds", "Sad Autumn Leaves").

The fourth stage was aimed at mastering the techniques of contact improvisation (pair, group type).

Children were taught spontaneous dance based on an improvised image, for example, they were asked to imitate the movements of animals, swaying trees in the rain and snow. Contact improvisation was used with mastering the basic skills of pair dancing with objects, toys on a given topic or image, for example, squirrels playing with nuts, dolphins playing with balls. Associative games were used: children were asked to depict various objects and 
phenomena in pair dance (raindrops, clouds, leaves fluttering in the wind, interweaving of tree branches in the wind).

The children's motor fantasies reflected the emerging creative connection between sound, gesture and movement. Pair and group dance made it possible to set more complex motor tasks of coordination and space orientation development. The data obtained in the control experiment made it possible to obtain the following results (Table 1).

Table 1. Distribution of subjects from the experimental (EG) and control groups (CG) by psychomotor development levels in accordance with the results of the ascertaining and control experiments.

\begin{tabular}{|c|c|c|c|c|c|c|c|c|c|}
\hline \multirow{2}{*}{ Groups } & $\begin{array}{c}\text { Psychomotor } \\
\text { development } \\
\text { levels }\end{array}$ & \multicolumn{2}{|c|}{ High level } & \multicolumn{2}{c|}{$\begin{array}{c}\text { Average } \\
\text { level }\end{array}$} & \multicolumn{2}{c|}{ Low level } & \multicolumn{2}{|c|}{ In total } \\
\cline { 2 - 11 } & Experiment type & people & $\%$ & people & $\%$ & people & $\%$ & people & $\%$ \\
\hline \multirow{4}{*}{ EG } & $\begin{array}{c}\text { Ascertaining } \\
\text { experiment }\end{array}$ & 3 & 2.5 & 41 & 33.9 & 77 & 63.6 & 121 & 100 \\
\cline { 2 - 12 } & $\begin{array}{c}\text { Control } \\
\text { experiment }\end{array}$ & 9 & 7.5 & 69 & 57.0 & 43 & 35.5 & 121 & 100 \\
\hline \multirow{3}{*}{ CG } & $\begin{array}{c}\text { Ascertaining } \\
\text { experiment }\end{array}$ & 20 & 14.9 & 84 & 62.2 & 31 & 22.9 & 135 & 100 \\
\cline { 2 - 11 } & $\begin{array}{c}\text { Control } \\
\text { experiment }\end{array}$ & 26 & 19.4 & 85 & 62.9 & 24 & 17.7 & 135 & 100 \\
\hline
\end{tabular}

Table 1 shows the positive dynamics of preschoolers' psychomotor development levels. In the EG, there are pronounced positive dynamics. The ascertaining experiment showed the predominance of a low level of psychomotor development in mentally retarded children (63.6\%), while the control experiment revealed the predominance of an average level of psychomotor development $(57.0 \%)$. The percentage of children with a high level of psychomotor development has increased (from $2.5 \%$ to $7.5 \%$ ). The positive shift is statistically significant $\left(\chi^{2}=46.4, p=0.001\right)$. In the $C G$, there is also a positive statistically insignificant dynamics in the effectiveness of psychomotor tests $\left(\chi^{2}=3.39, p>0.05\right)$.

The program "Music and Dance of My Body", developed to optimize the psychomotor development of mentally retarded children, has shown high efficiency in actualizing developmental opportunities. There were qualitative changes in psychomotor skills: indicators of static and dynamic coordination increased; speed, clarity, and smoothness of movements increased; possibilities of perception and memorization of movements, as well as mimic and pantomimic expressiveness increased; synchronicity of movements increased significantly.

\section{Conclusions}

Thus, the musical-motor improvisation program "Music and Dance of My Body" effectively solves a set of tasks for the psychomotor development of mentally retarded children.

Positive developmental results confirm the role of movement as a trigger mechanism for the development. In the process of program implementation, there have been positive changes in children's mimic and pantomimicry, movements have become more diverse and lively, the possibilities of voluntary movement regulation have increased; motor skills and spatial coordination of movements have improved. There were changes in children's activity and emotional expressiveness: the movements have become more confident, accuracy, clarity, the amplitude and smoothness of movements have increased. According 
to the results of the control test, the dynamics of development are statistically significant at the high level $\left(\chi^{2}=46.4, \mathrm{p}=0.001\right)$.

One-third of mentally retarded children remained at a low level of psychomotor development. The study of medical records makes it possible to explain these results with a more complex medical diagnosis of impaired maturation and functional impairment in this group of children.

\section{References}

1. N.V. Shutova, Integrated mental development of troubled children of senior preschool age through musical influence. Thesis for the degree of Doctor of Psychology (Nizhny Novgorod State Pedagogical University, Nizhny Novgorod, 2009)

2. N.V. Shutova, O.V. Suvorova, L.V. Guseva, The Fifth International Luria Memorial Congress "Lurian Approach in International Psychological Science". 804-813 (2018) doi: 10.18502/kls.v4i8.3338

3. S.N. Mukhina, Scientific Search 1, 92-5 (2017).

4. G.A. Butko, O.V. Suvorova, S.N. Sorokoumova, Minin University Bulletin 7 (3) (28), 6 (2019).

5. I.Yu. Levchenko, O.G. Prikhodko, Technologies for teaching and upbringing of children with musculoskeletal disorders (Akademiya, Moscow, 2001)

6. K.A. Semyonova, E.M. Mastyukova, M.Ya. Smuglin, Clinic and rehabilitation therapy for children with cerebral palsy (Knigapotrebovaniyu, Moscow, 2013)

7. A.R. Luria, Lectures on general psychology (Piter, St. Petersburg, 2006)

8. A.V. Zaporozhets, Psychology of action. Selected psychological works (MPSI, Moscow, 2000)

9. I.I. Mamaichuk, Psychological assistance to children with developmental problems (Rech, St. Petersburg, 2001)

10. E.G. Schellenberg, T. Nakata, G. Hunter, S. Tamoto, Psychology of Music 35 (5), 519 (2007).

11. T. Fujioka, B. Ross, R. Kakigi, C. Pantev, L.J. Trainor, Brain 129, 2593-2608 (2006).

12. Zh.M. Glozman, A.E. Pavlov, Psychological Science and Education 3, 36-46 (2007).

13. Y.C. Ho, M.C. Cheung, A.S. Chan, Neuropsychology 17, 439-450 (2003).

14. S. Moreno, M. Besson, Psychophysiology 43, 287-291 (2006).

15. S. Hallam, International Journal of Music Education 28 (3), 269-289 (2010).

16. L.O. Ulfarsdottir, P.G. Erwin, The Arts in Psychotherapy 26 (2), 81-84 (1999).

17. E. Zachopouloua, A. Tsapakidoub, V. Derric, Early Childhood Research 19, 631-642 (2004).

18. L. Kanner, Nervous Child 2, 217-250 (1943).

19. N. Ziv, M. Goshen, British Journal of Music Education 23 (3), 303-314 (2006). doi:10.1017/S0265051706007078

20. M. Hogenes, B.V. Oers, R.F. Diekstra, The European Journal of Social \& Behavioural Sciences 10, 1507-1526 (2014). http://dx.doi.org/10.15405/ejsbs. 135

21. E. Zachopouloua, A. Tsapakidoub, V. Derric, Early Childhood Research 19, 631-642 (2004). 
22. I.M. Sechenov, Selected philosophical and psychological works (State Publishing House of Political Literature, Moscow, 1947)

23. V.V. Medushevsky, On the patterns and means of artistic influence of music (Muzyka, Moscow, 1976) 